\title{
ANÁLISE DA PRECIPITAÇÃO PLUVIAL NA BACIA DO PARANAPANEMA
}

\author{
Jonas Teixeira Nery ${ }^{27}$ \\ Ana Claudia Carfan 28 \\ Tatiana Mascari Parizotto 29
}

\begin{abstract}
RESUMO
O objetivo deste trabalho foi estudar a variabilidade pluviométrica na bacia hidrográfica do rio Paranapanema, analisando anomalias das chuvas ao longo de um período climatológico, assim como a relação dessa variável meteorológica com os períodos de ocorrência dos fênomenos El Niño e La Niña e sua variabilidade espacial. Os dados de precipitação de 1975 a 2004 foram retirados do site da Agência Nacional de Águas (ANA). Foram escolhidas 96 estações ao longo da bacia hidrográfica dos Estados de São Paulo e Paraná e realizadas análises estatísticas (média, desvio-padrão, coeficiente de variação e amplitude) visando comparar os padrões climatológicos durante períodos chuvosos e secos, respectiv'amente, no intervalo de estudo deste trabalho. Calcularam-se as anomalias anuais, as quais foram relacionadas aos períodos de El Niño e La Niña mais intensos. A partir da análise de componentes principais e análise de cluster foram definidas áreas homogêneas dentro da bacia. Por se tratar de um método subjetivo de classificação, optou-se por estabelecer cinco regiões com características diferenciadas dentro da área de estudo. Assim, de acordo com as estatísticas realizadas, a precipitação pluvial apresenta significativa variabilidade na área de estudo, com invernos secos e verões chuvosos. A bacia apresenta, em períodos de ocorrência dos fenômenos El Niño e La Niña, variabilidade pluviométrica espacial e temporal bem marcadas para alguns eventos.
\end{abstract}

Palavras-chaves: precipitação pluvial, bacia do Paranapanema, variabilidade.

\begin{abstract}
The purpose of this work was to study the pluviometric variability in Paranapanema hydrographic basin, analyzing rainfall anomalies along a climatic period, as well as examining the relation of this meteorological variable with years of El Niño and La Niña, and its spatial variability. The rainfall data from 1975 to 2004 were collected from the site of Agência Nacional da Água (ANA). 96 seasons along the hydrographic basin of São Paulo and Paraná states were chosen. Statistical analyses (average, standard deviation, variation coefficient

27 Professor Doutor, UNESP_Ourinhos, Geografia, jonas@ourinhos.unesp.br.

28 Doutoranda, USP, Geografia, acarfan@terra.com.br.

${ }^{29}$ Bolsista da FAPESP.
\end{abstract}


and amplitude) were used, with the objective of comparing the climatic patterns, rainy and dry periods, in the study interval of this work. The annual anomalies were calculated and related to the most intense periods of El Niño and La Niña. Through the analysis of the main components and the study of cluster, homogeneous areas were defined inside the basin. As it is a subjective method of classification, we opted to establish five regions with different characteristics, inside the area of study. Thus, according to the statistics accomplished, the rainfall shows significant variability in this area of analysis, with dry winters and rainy summers. The basin presents, in periods of occurrence of El Niño and La Niña phenomena, spatial and temporal rainfall variability, expressive for some events.

Key-words: rainfall, Paranapanema basin, variability.

\section{INTRODUÇÃO}

A precipitação pluvial constitui-se em uma das variáveis climáticas que maior influência exerce sobre a qualidade do meio ambiente. As quantidades relativas de chuvas, seu regime sazonal ou diário e a intensidade de chuvas individuais são algumas das características que afetam direta ou indiretamente a população, a economia e o meio ambiente.

A composição do quadro climático regional está relacionada aos sistemas dinâmicos atuantes e aos elementos da paisagem geográfica, tais como o relevo, a latitude, a maritimidade e a continentalidade. A pluviosidade, portanto, é condicionada pela dinâmica atmosférica em relação ao relevo que, por meio de sua compartimentação, promove a distribuição espacial da chuva.

De acordo com Mendonça (2007), a distribuição e a variabilidade das chuvas no Brasil estão associadas à atuação e à sazonalidade dos sistemas convectivos de macro e mesoescala e, em especial, da frente polar atlântica (FPA). Isso explica as diferenças entre os regimes pluviométricos encontrados que se expressam na diversidade climática do País e os tipos chuvosos, semiáridos, tropicais e subtropicais. No entanto, tal distribuição pode sofrer interferências de outros fenômenos climáticos, como El Niño e La Niña, por exemplo.

A bacia do Paranapanema está localizada entre as regiões Sul e Sudeste do Brasil, caracterizando-se, assim, como uma fronteira natural entre os Estados de São Paulo e Paraná, razão pelo qual suas características climáticas são bastante diversificadas.

O Sudeste, por conta de sua localização latitudinal, caracteriza-se como uma região de transição entre os climas quentes de latitudes baixas e os climas mesotérmicos de tipo temperado das latitudes médias. (NIMER, 1979) O sul da região Sudeste, assim como o da Centro-Oeste, é afetado pela maioria dos sistemas sinóticos que atingem o sul do país, com algumas diferenças em termos de intensidade e sazonalidade do sistema.

Segundo Mendonça e Danni-Oliveira (2007), as regiões Sul e Sudeste figuram os macrotipos climáticos conhecidos como clima tropical do Brasil Central sem seca e clima subtropical úmido com inverno fresco a frio, respectivamente. A bacia do Paranapanema se encontra, portanto, na transição entre esses dois tipos climáticos, o que torna a área de estudo mais heterogênea e complexa. 
A região Sudeste apresenta chuva em todos os meses do ano, tendo maior concentração no verão e redução no inverno. As localidades desse subtipo climático são bastante influenciadas pelos sistemas atmosféricos oceânicos tropicais ( $\mathrm{mTa}$ ) e polares $(\mathrm{mPa})$, que respondem pela pluviosidade e pela variabilidade térmica em todos os meses do ano.

Ainda de acordo com Mendonça e Danni-Oliveira (2007), a região Sul também é controlada por massas de ar tropicais e polares. A massa equatorial continental (mEc) também atua na formação desse tipo climático. Uma das principais características dessa região brailseira é sua maior regularidade na distribuição anual da pluviometria associada às baixas temperaturas do inverno.

O fenômeno El Niño (Oscilação Sul) tem sua origem situada no Oceano Pacífico tropical. Dois componentes constituem o fenômeno, sendo um de natureza oceânica e outro de natureza atmosférica, este último relacionado à correlação inversa existente entre a pressão atmosférica nos extremos Leste e Oeste desse oceano, induzindo, assim, profundas modificações climáticas na região tropical e em várias regiões do globo terrestre. (GRIMM et al., 1997).

A relação existente entre o El Niño - Oscilação Sul (ENOS) - e a precipitação é conhecida e tem sido bastante estudada. No Brasil, algumas anomalias de precipitação podem estar associadas ao fenômeno El Niño (Oscilação Sul). Kousky e Cavalcanti (1984) concluíram que, durante o período de ocorrência do El Niño entre 1982 e 1983 (fase negativa da Oscilação Sul), uma corrente de jato subtropical bem marcada sobre a América do Sul e a Oeste do Pacífico Sul, juntamente com várias situações de bloqueio, em latitudes médias, favoreceram o ingresso de sistemas frontais ativos no Sul do Brasil. Isso explicaria a excessiva precipitação observada na região durante tal período.

Studzinski (1995) relacionou as precipitações no Sul do Brasil às temperaturas dos oceanos Pacífico e Atlântico Tropical e Sul. O autor concluiu que o El Niño (Oscilação Sul) desempenha um importante papel na variabilidade interanual das precipitações pluviométricas dessa região, atuando em praticamente todos os meses do ano.

Nery et al. (1997) observaram que todas as flutuações interanuais mais significativas da precipitação no Estado do Paraná estiveram associadas às fases extremas de Oscilação Sul. As secas mais significativas ocorreram no inverno e nem sempre havia ligação com a fase La Niña.

Os estudos relacionados à dinâmica climatológica atuante na crosta terrestre especificadamente na área da bacia hidrográfica do Paranapanema, podem colaborar para os planejamentos em diversos setores da economia e, principalmente, na geração de energia elétrica, uma vez que o domínio sobre o conhecimento climático tornou-se uma prerrogativa importante para desenvolvimento desses segmentos e, também, para a agricultura. Além disso, é possível disponibilizar informações concernentes a anomalias, favorecendo o aproveitamento das condições climáticas constatadas. A análise climatológica favorece subsídios importantes, tanto no que diz respeito ao conhecimento da realidade espacial quanto à organização das atividades econômicas, permitindo a integração de diversas modalidades que possibilitam aperfeiçoar os estudos na questão ambiental. Com isso, na área de estudo selecionada, analisou-se a variabilidade da precipitação pluvial em um intervalo de 30 anos (de 1975 a 2004), em períodos sazonais e períodos eventuais de ocorrência de El Niño e La Niña. Verificou-se, também, as possíveis áreas homogêneas existentes dentro da bacia, as quais apresentam regimes pluviométricos semelhantes. 


\section{MATERIAL E MÉTODO}

A coleta de dados de precipitações pluviais diárias foi realizada a partir dos postos pluviométricos mencionados no banco de dados do site da Agência Nacional de Águas (ANA), Hidroweb. A busca resultou em 96 estações ao longo da área da bacia hidrográfica do Paranapanema, tanto no Estado de São Paulo quanto no Paraná, destacando-se significativa distribuição espacial das estações, que foram muito mais densas no Estado de São Paulo - em comparação ao Norte do Paraná -, em virtude da falta de compatibilidade dos postos pluviométricos no período analisado (1975-2004).

As séries selecionadas foram organizadas em tabelas incluindo dados mensais e cálculos estatísticos (média, desvio-padrão, coeficiente de variação e amplitude), a fim de comparar o padrão climatológico e o período chuvoso e seco para os 30 anos.

Pode-se afirmar que a medida de dispersão seja uma medida da variação de um conjunto de dados em torno da média, ou seja, da maior ou menor variabilidade dos resultados obtidos, permitindo identificar até que ponto os resultados se concentram ou não ao redor da tendência central de um conjunto de observações. A amplitude, o desvio médio, o desvio-padrão, o erropadrão e o coeficiente de variação, cada um expressa diferentes métodos para quantificar a tendência que os resultados de um experimento aleatório têm de se concentrarem ou não em determinados valores (quanto maior a dispersão, menor a concentração e vice-versa).

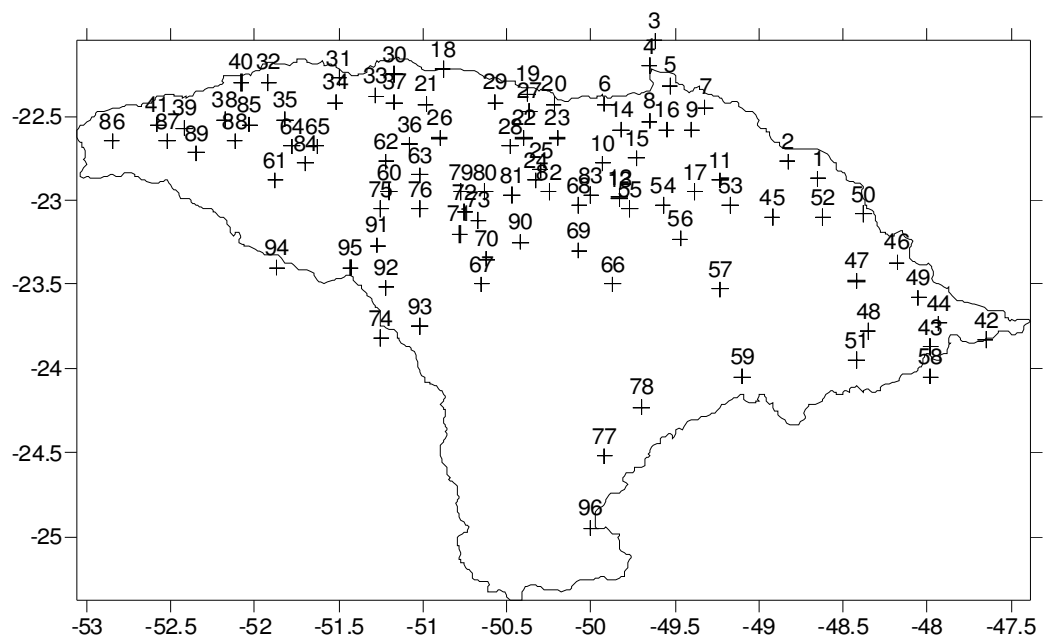

Figura 1: Localização dos postos pluviométricos na bacia do Paranapanema, situados entre os Estados de São Paulo e Paraná.

O desvio-padrão mede a dispersão dos dados, comumente denominada, na área de climatologia, variabilidade da série analisada.

Para os cálculos sazonais foram selecionados os meses de dezembro, janeiro e fevereiro para o período chuvoso, e junho, julho e agosto para o período seco.

Com base na média aritmética foram calculadas as anomalias anuais $\left(X_{i}-\bar{X}\right)$, as quais refletem o quanto cada mês ou ano se afastou do valor médio (da média climatológica). Esses afastamentos podem ser negativos 
(período mais seco) ou positivos (período mais úmido). Os cálculos de anomalias foram então comparados aos anos de ocorrência de El Niño e La Niña, nos períodos de maior intensidade, com o objetivo de analisar os períodos de tais eventos em relação à área de estudo, utilizando a tabela de classificação desses fenômenos de acordo com o Centro de Previsão do Tempo e do Clima (CPTEC).

Tabela 1 - Anos de eventos El Niño e La Niña

\begin{tabular}{|c|c|c|c|}
\hline El Niño & Intensidade & La Niña & Intensidade \\
\hline $1877-1878$ & Forte & 1886 & Forte \\
\hline $1888-1889$ & Moderada & $1903-1904$ & Forte \\
\hline $1896-1897$ & Forte & $1906-1908$ & Forte \\
\hline 1899 & Forte & $1909-1910$ & Forte \\
\hline $1902-1903$ & Forte & $1916-1918$ & Forte \\
\hline $1905-1906$ & Forte & $1924-1925$ & Moderada \\
\hline $1911-1912$ & Forte & $1928-1929$ & Fraca \\
\hline $1913-1914$ & Moderada & $1938-1939$ & Forte \\
\hline $1918-1919$ & Forte & $1949-1951$ & Forte \\
\hline 1923 & Moderada & $1954-1956$ & Forte \\
\hline $1925-1926$ & Forte & $1964-1965$ & Moderada \\
\hline 1932 & Moderada & $1970-1971$ & Moderada \\
\hline $1939-1941$ & Forte & $1973-1976$ & Forte \\
\hline $1946-1947$ & Moderada & $1983-1984$ & Fraca \\
\hline 1951 & Fraca & $1984-1985$ & Fraca \\
\hline 1953 & Fraca & $1988-1989$ & Forte \\
\hline $1957-1959$ & Forte & $1995-1996$ & Fraca \\
\hline 1963 & Fraca & & Fraca (98 - 99) \\
\hline $1965-1966$ & Moderada & $1998-2001$ & Fraca (99 - 00) \\
\hline $1968-1970$ & Moderada & & Moderada (00 - 01) \\
\hline $1972-1973$ & Forte & & \\
\hline 1976 & Fraca & & \\
\hline $1977-1978$ & Fraca & & \\
\hline $1979-1980$ & Fraca & & \\
\hline $1982-1983$ & Forte & & \\
\hline $1986-1988$ & Moderada & & \\
\hline $1990-1993$ & Forte & & \\
\hline $1994-1995$ & Moderada & & \\
\hline $1997-1998$ & Forte & & \\
\hline $2002-2003$ & Fraca & & \\
\hline
\end{tabular}

Fonte: CPTEC/I $\overline{\mathrm{NPE}}$

Foram classificados grupos homogêneos por meio da técnica estatística (análise de cluster) amplamente utilizada em climatologia durante a identificação de regiões homogêneas, a partir de variáveis meteorológicas, possibilitando detectar áreas com variabilidades distintas dentro do objeto de 
estudo. As variáveis de entrada para a análise aplicada à matriz de totais anuais de precipitação no modo $\mathrm{S}$ foram as coordenadas das primeiras componentes principais (CP), gerando 29 fatores que totalizam $100 \%$ dos dados retidos na análise de componentes principais (ACP). Esse procedimento foi realizado com o software Statistica 7.

Depois de explicadas as variâncias procedeu-se à análise multivariada método de Ward - com distância euclidiana, determinado cinco grupos homogêneos, os quais possibilitaram o cálculo de alguns parâmetros estatísticos como média, máximo, mínimo, amplitude, desvio-padrão, coeficiente de variação e amplitude interquartil para cada um das áreas obtidas.

\section{DISCUSSÃO E RESULTADOS}

\section{Padrão climatológico, período chuvoso e seco}

A fim de definir um padrão meteorológico para a bacia do Paranapanema e relacioná-los a períodos chuvosos e secos foram utilizados alguns parâmetros estatísticos para o período de 1975 a 2004.

Assim, de acordo com as isolinhas traçadas em relação à média pluviométrica do período em análise, constatou-se que a Sudoeste da bacia, a quantidade de chuvas é maior que nas outras localidades da mesma, obtendo 2.500 mm de precipitação pluvial, conforme ilustra a Figura 2.

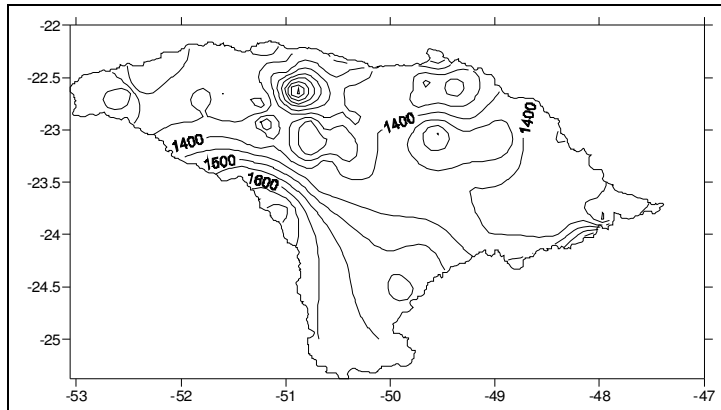

Figura 2: Média da precipitação pluvial na bacia no período de 1975 a 2004.

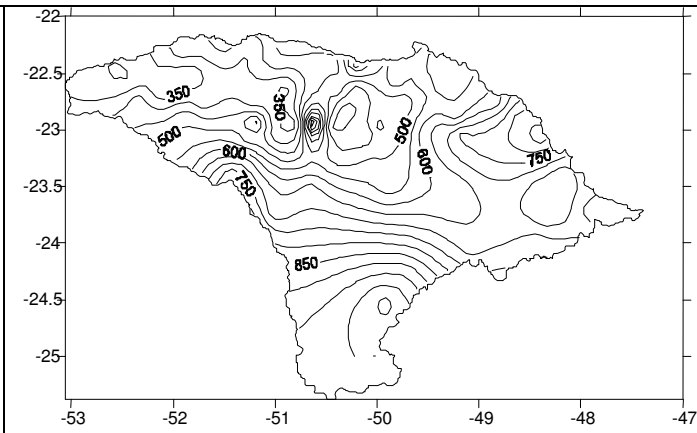

Figura 3: Altitudes, em metros, na bacia.

Um dos fatores que influenciam essa precipitação pluvial é a orografia marcada nessa porção da bacia, chegando a $850 \mathrm{~m}$ de altitude, conforme a Figura 3. Tal fator provoca as chamadas chuvas orográficas que, combinadas à entrada de sistemas frontais provenientes da região polar durante todo o ano e com os sistemas convectivos, na primavera e verão, acabam por carrear a umidade da Amazônia para as regiões Sul e Sudeste e aportá-la para a bacia. Desse modo, o relevo atua como uma forçante, provocando chuva na região.

Na Figura 3 é possível observar que há significativa variação altimétrica na bacia. As áreas mais elevadas encontram-se entre 750 e $850 \mathrm{~m}$ e a montante, $350 \mathrm{~m}$, sendo possível observar uma declividade acentuada entre a nascente e a foz do principal rio da bacia.

Com base nos cálculos de desvio-padrão e coeficiente de variação pode-se observar que houve uma significativa variabilidade, alcançando valores 
de, aproximadamente, 20 a 30\% de variabilidade em relação ao coeficiente de variação, conforme ilustrado nas Figuras 4 e 5.

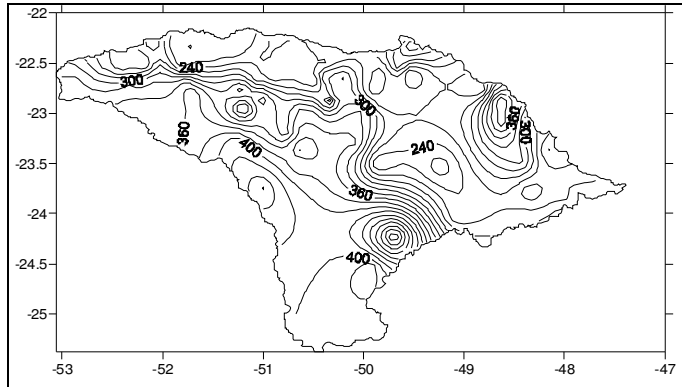

Figura 4: Isolinhas do desvio-padrão no período de 1975 a 2004.

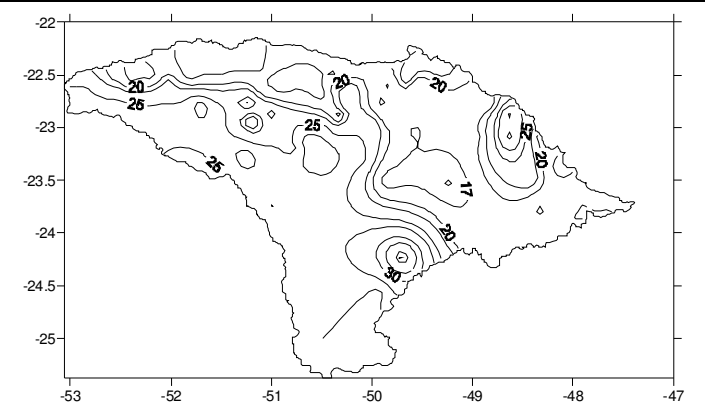

Figura 5: Isolinhas do coeficiente de variação no período de 1975 a 2004.

É possível que tais amplitude sejam geradas pelo tipo de uso e ocupação do solo. No Estado de São Paulo há uma preservação maior de áreas verdes, enquanto no Paraná a prática da agricultura vem provocando desmatamentos, sem que haja preocupação com a preservação, o que, consequentemente, aumenta a amplitude entre máxima e mínima de chuva, conforme pode ser observado na Figura 6.

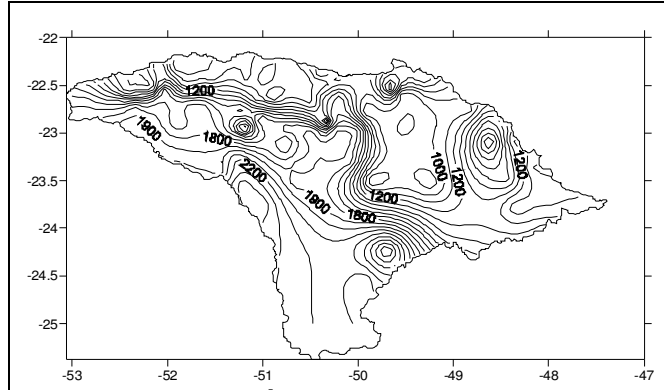

Figura 6: Média da amplitude entre o valor máximo e mínimo de precipitação.

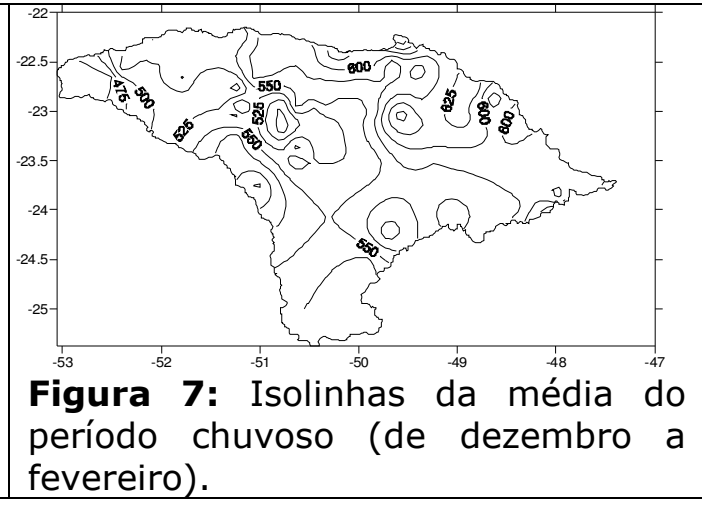

Para a análise do período chuvoso foram considerados os meses de dezembro, janeiro e fevereiro. Para o período seco, por sua vez, foram considerados os meses de junho, julho e agosto.

De acordo com as Figuras 7 e 8, ao Norte e sobretudo ao Nordeste da bacia a precipitação pluvial é maior em períodos de chuva, ao passo que no período seco ela incide mais sobre o Sul. Convém ressaltar que, nos dois períodos, essa bacia encontra-se sob influência de sistemas frontais provenientes do extremo Sul do continente sul-americano. No período chuvoso, além das massas polares, ocorre a entrada da umidade que vem da Amazônia. Parte da bacia também sofre influência das massas tropicais continentais oriundas da região do Chaco, evolvendo o pantanal do Mato Grosso, a região do Chaco boliviano e o Paraguai. Os sistemas convectivos presentes nesse período provocam mais chuvas intensas associadas a nuvens cumulunimbus. As zonas de convergência que atuam no intervalo que vai de outubro até março são importantes para a gênese de chuvas intensas, não somente na bacia, como em 
toda a região Sul e Sudeste do Brasil. Associados às frentes frias tais sistemas são forçados a se elevarem, pois são mais quentes e úmidos, muitas vezes gerando chuvas intensas. Já no período seco as chuvas são mais estratiformes, provocadas pelas massas polares. Trata-se de chuvas contínuas, as quais não geram precipitações pluviais intensas. Nesse período não se observa a atuação dos sistemas provenientes da Amazônia e a baixa do Chaco se desintensifica.

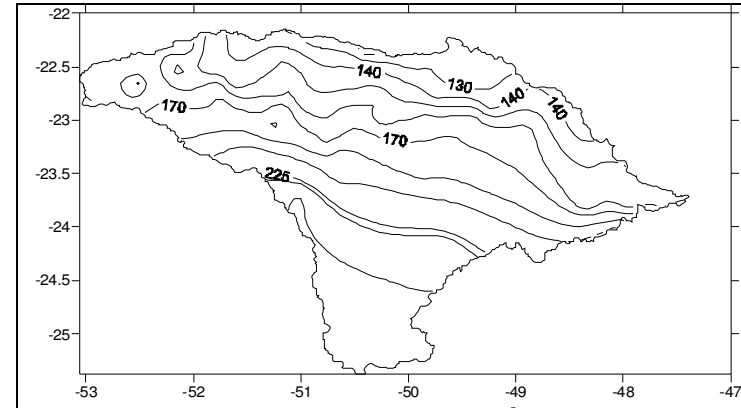

Figura 8: Isolinhas do período seco (de junho a agosto).

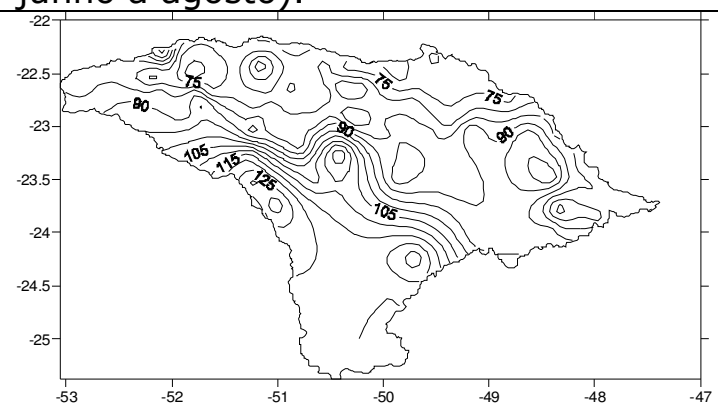

Figura 10: Isolinhas dos desvios do período seco (de 1975 a 2004).

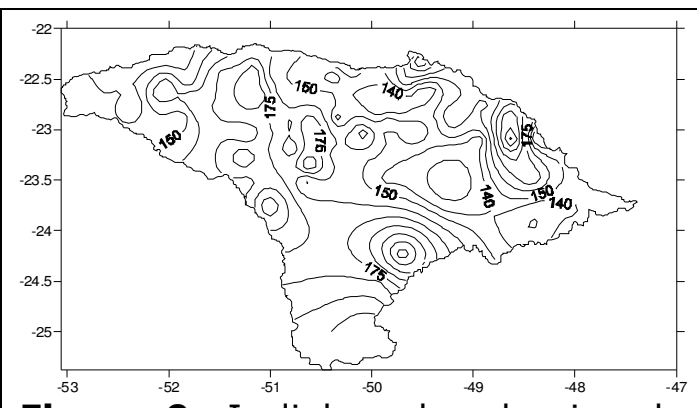

Figura 9: Isolinhas dos desvios do período chuvoso (de 1975 a 2004).

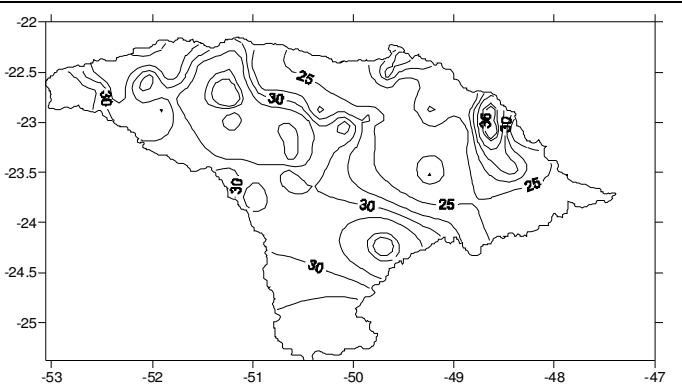

Figura 11: Isolinhas dos coeficientes de variação para o período chuvoso.

Nas Figuras 9 e 10 é possível observar que o desvio-padrão do período seco apresenta um intervalo maior em comparação ao período chuvoso, principalmente a Sudoeste e a Sul da bacia. Pode-se inferir que existe maior variabilidade nesse período, ao passo que o coeficiente de variação é muito mais significativo no período seco, variando de 55 a $65 \%$ a Leste da área de estudo em questão. Nos períodos chuvosos essa variação não ultrapassa os $30 \%$, conforme ilustram as Figuras 11 e 12.

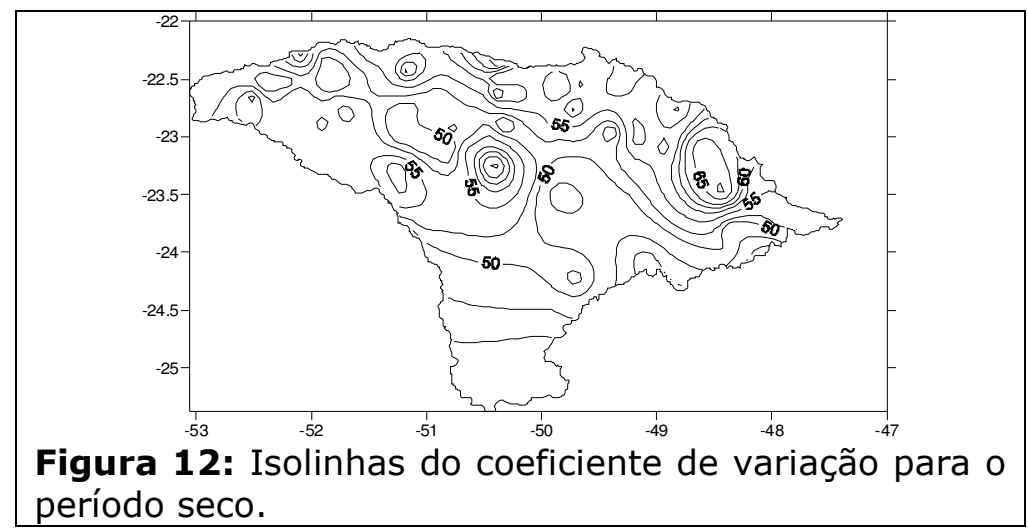




\section{Análise das anomalias}

A partir do cálculo das anomalias é possível observar significativa variabilidade espacial e temporal dentro da área de estudo, com alguns anos apresentando anomalias positivas espacialmente distribuídas, outros com anomalias negativas e alguns com valores positivos e negativos espacialmente distribuídas, no mesmo período. Tais anomalias mostram o quanto choveu em relação ao valor médio climatológico (Figura 2 ).

Os anos de 1982 e 1983 foi um período de El Niño intenso. Nas Figuras 13 e 14 observam-se anomalias positivas e verifica-se que a ocorrência do evento influenciou toda a bacia, com chuvas acima da média climatológica, principalmente no ano de 1983, apresentando valores superiores a $1.300 \mathrm{~mm}$ na região Leste da bacia. Por outro lado, a Sudeste é possível observar anomalias negativas em um pequeno núcleo, demonstrando que ainda há variabilidade espacial para manifestações intensas do El Niño.

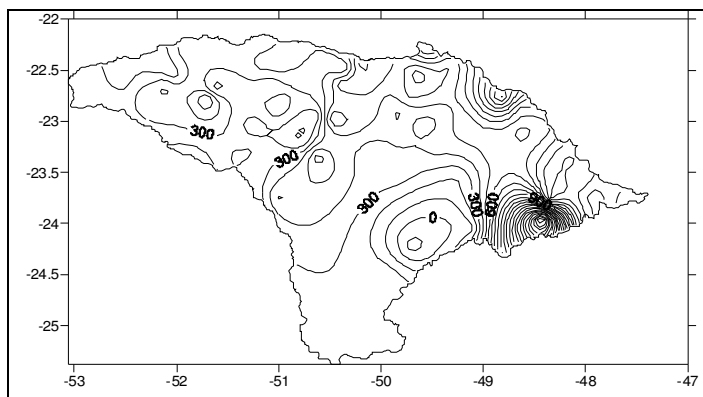

Figura 13: Ano de 1982 (El Niño).

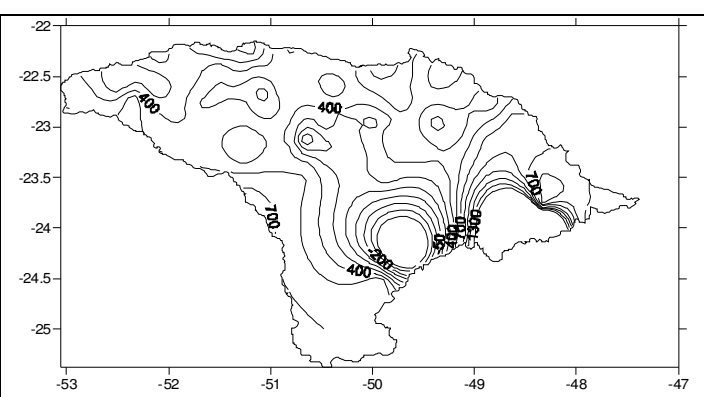

Figura 14: Ano de 1983 (El Niño).

O período entre 1990 e 1993 contou com a ocorrência de forte manifestação do fenômeno El Niño, embora na bacia em estudo os anos de 1990 e 1992 (Figuras 15 e 17) tenham apresentado pouca variabilidade pluviométrica em relação à média climatológica, variando em até $200 \mathrm{~mm}$ e possuindo muitos núcleos, como ao norte da bacia, onde a variação chegou a ser nula.

Já nos anos de 1991 e 1993 (Figuras 16 e 18) as variações foram mais diferenciadas e intensas. Em 1991 houve uma anomalia positiva intensa na porção Sudeste da área em estudo, enquanto nas regiões Sul e Sudoeste as anomalias foram negativas, refletindo menor quantidade de chuvas com relação à média climatológica. Na região central da bacia as anomalias foram nulas.

Para os anos de 1997 e 1998 (Figuras 19 e 20) as anomalias foram positivas, mas verificou-se uma variabilidade espacial ao longo da área em estudo, com amplitude pluvial bem marcada.

O ano de 1985 foi um dos anos em que ocorreram manifestações mais intensas do fenômeno La Niña, como mostra a Figura 21, as quais exerceram uma forte influência sobre toda a bacia do Paranapanema, onde todos os valores pluviométricos ficaram abaixo da média climatológica da bacia, sendo mais intensos na parte Sudeste da mesma.

O deslocamento dos jatos subtropicais para a porção mais ao Sul da região Sul do Brasil atenuando o avanço das frentes frias em direção ao interior fazendo com que essas frentes se desloquem para o Oceano Atlântico. 

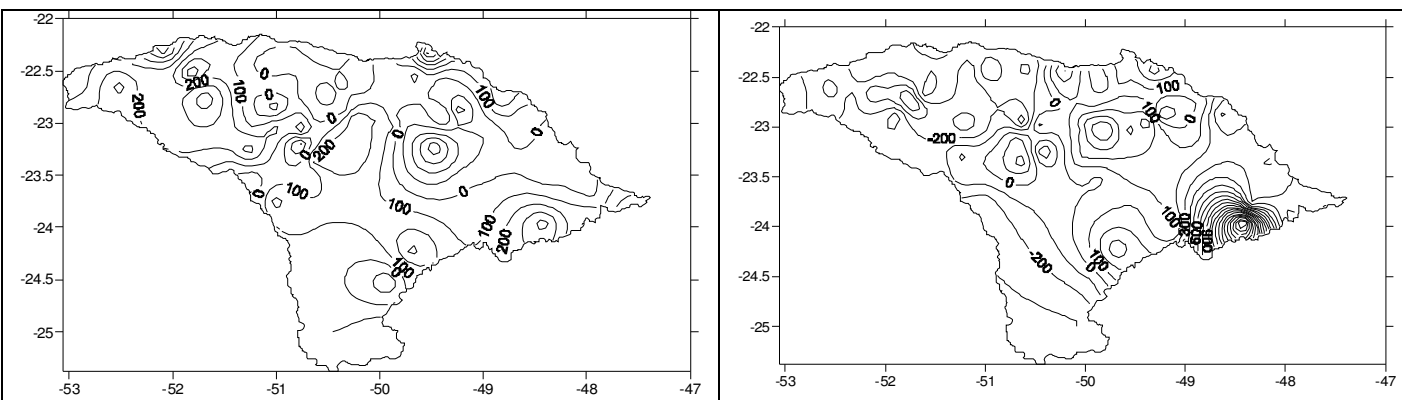

Figura 15: Ano de 1990 (El Niño).

Figura 16: Ano de 1991 (El Niño).
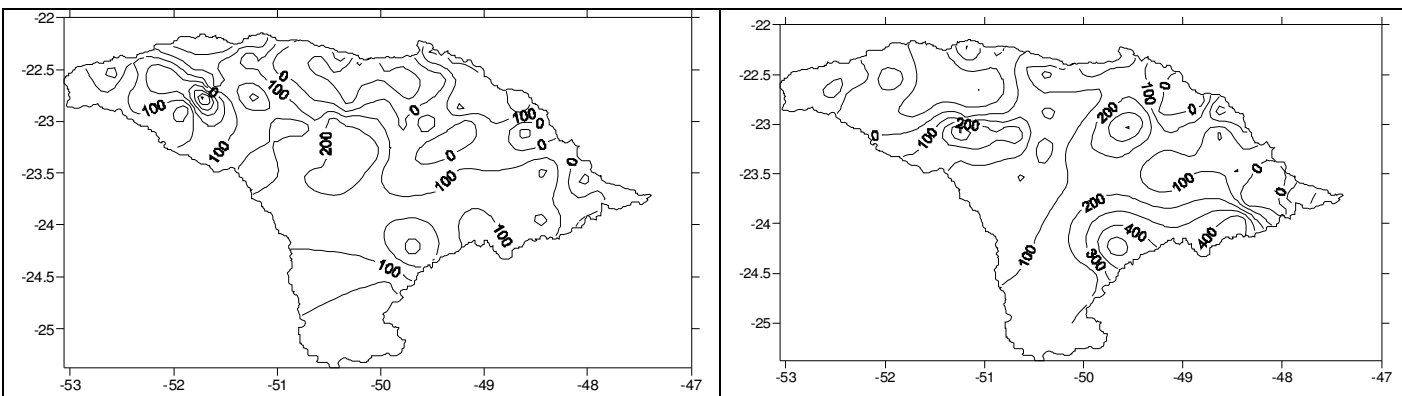

Figura 17: Ano de 1992 (El Niño).

Figura 18: Ano de 1993 (El Niño).
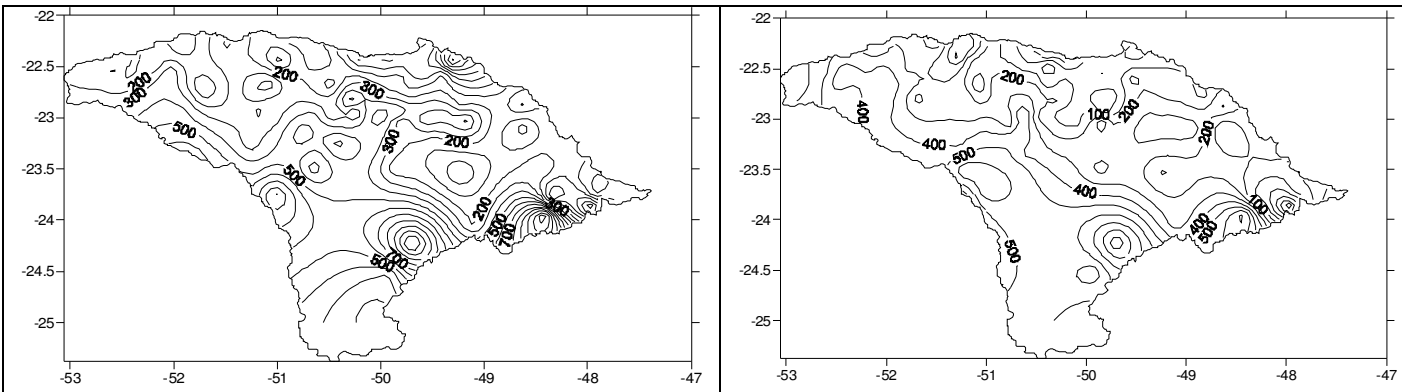

Figura 19: Ano de 1997 (El Niño).

Figura 20: Ano de 1998 (El Niño).

Os anos de 1988, 1989, 2000 e 2001 (Figuras 22 a 25) foram marcados por forte manifestação do fenômeno La Niña, sendo que os anos de 1988 e 2000 exerceram maior influência sobre a bacia, com valores abaixo da média climatológica. Já os anos de 1989 e 2001 obtiveram valores de precipitações positivas com alguns núcleos negativos, demonstrando pouca influência do evento.

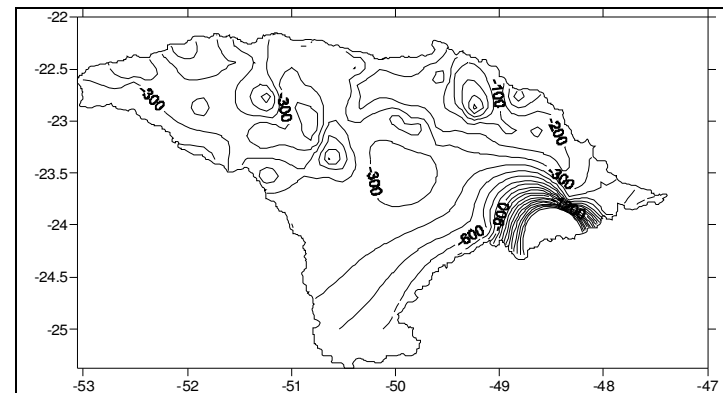

Figura 21: Ano de 1985 (La Niña).

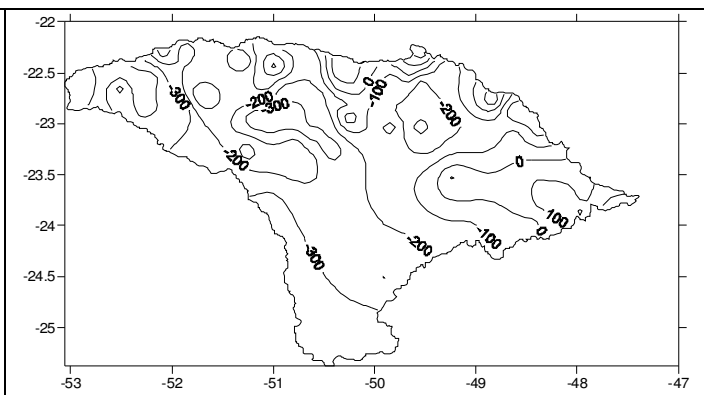

Figura 22: Ano de 1988 (La Niña). 


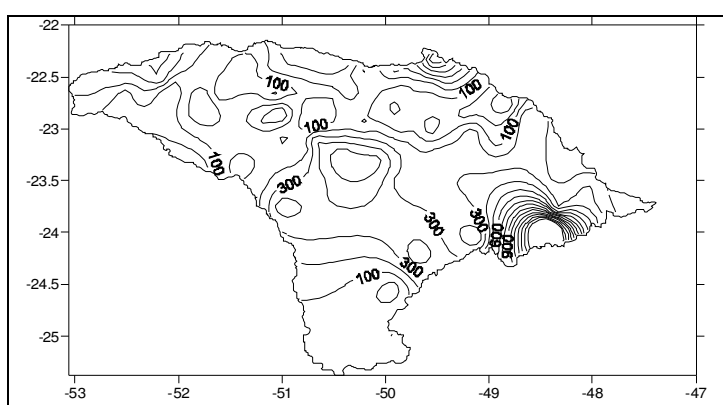

Figura 23: Ano de 1989 (La Niña).

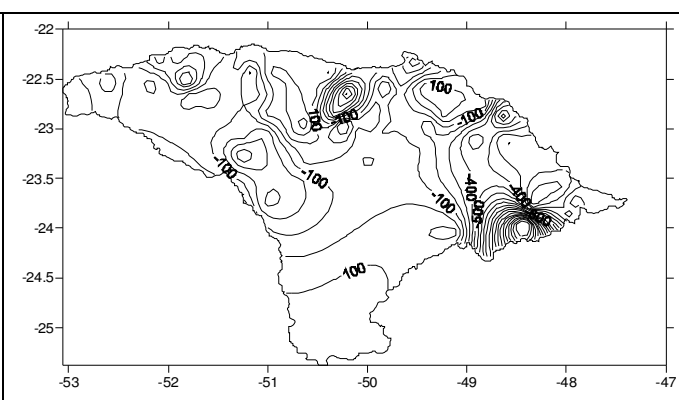

Figura 24: Ano 2000 (La Niña).

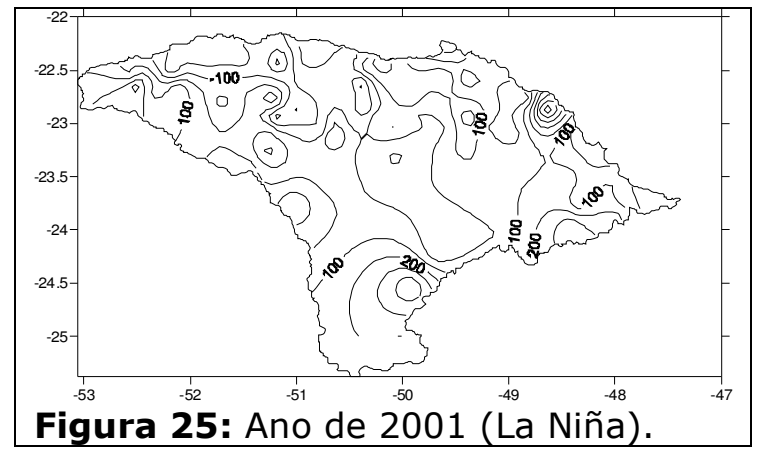

\section{Áreas homogêneas}

A partir da análise de componentes principais e da análise multivariada foram gerados cinco grupos homogêneos na bacia (Figura 26 e Tabela 2).

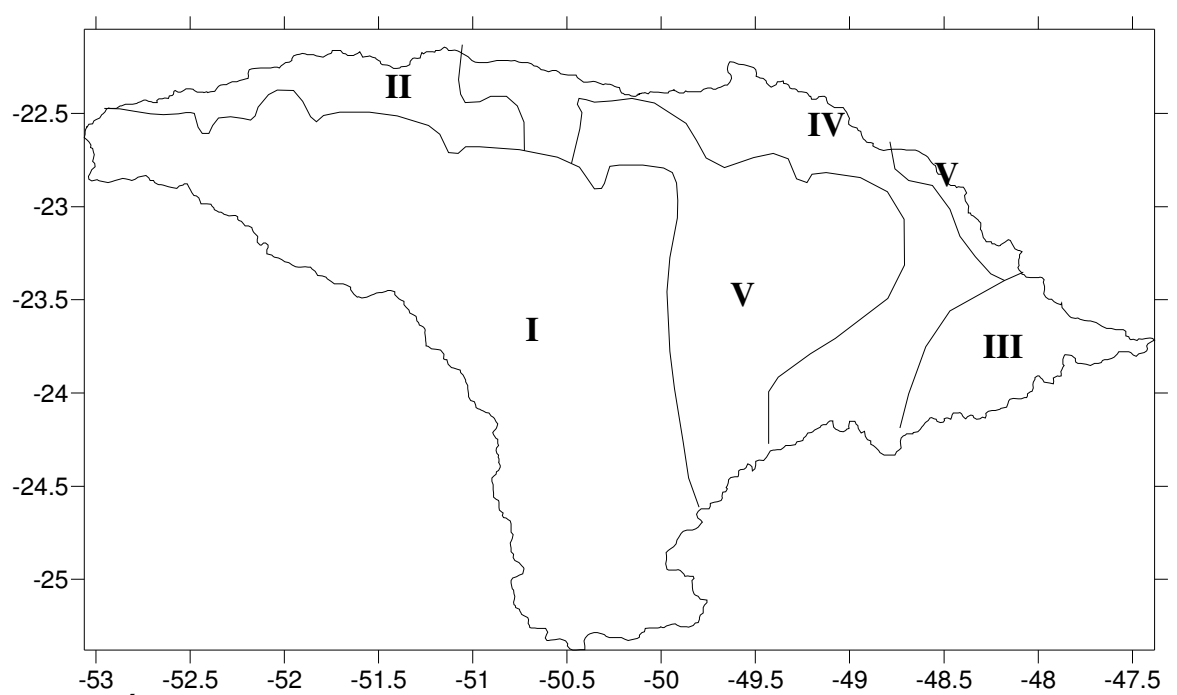

Figura 26: Áreas homogêneas classificadas através de análise de cluster, método de Ward, com distância euclidiana. 
Tabela 2 - Divisão dos grupos com os respectivospostos pluviométricos

\begin{tabular}{|c|c|}
\hline GRUPOS & No DAS ESTAÇÕES \\
\hline $\mathbf{I}$ & $\begin{array}{l}96,76,75,95,93,92,67,90, \\
73,72,80,79,71,63,91,82, \\
81,69,83,68,62,70,61,77, \\
87,89,86,88,85,94,74,84, \\
65,64\end{array}$ \\
\hline II & $\begin{array}{l}41,39,38,32,36,60,35,30, \\
37,31,34,33,26\end{array}$ \\
\hline III & $\begin{array}{l}40,43,5,58,44,51,49,48 \\
42,4\end{array}$ \\
\hline IV & $\begin{array}{l}52,47,11,9,19,8,20,21,7, \\
59,27,18,29,28,14,16,15, \\
6\end{array}$ \\
\hline $\mathbf{V}$ & $\begin{array}{l}66,57,24,25,23,50,46,55, \\
13,56,53,17,54,12,10,22, \\
3,45,1\end{array}$ \\
\hline
\end{tabular}

Os postos pluviométricos do grupo I estão todos localizados no Estado do Paraná e apresentou variabilidade, como mostra a Tabela 3, sendo que possui uma amplitude bem marcada, possivelmente devido à altitude, que varia de 500 a 850 m nessa área.

Nesse grupo obteve-se a menor e maior precipitação diante das outras áreas, conforme ilustra a Figura 26.

Tabela 3 - Cálculos estatísticos para cada um dos grupos gerados no dendograma. Máx. significa máxima precipitação pluvial em cada grupo; Min. corresponde à mínima precipitação pluvial em cada grupo; Amp. diz respeito à amplitude pluviométrica em cada grupo; DP refere-se ao desvio-padrão para cada área homogênea; CV é o coeficiente de variação de cada área homogênea classificada

\begin{tabular}{ccccccc}
\hline Grupos & Media & Máx. & Min. & Amp. & DP & CV(\%) \\
\hline I & 47.360 & 61.029 & 5.043 & 55.986 & 10.546 & 22,3 \\
II & 17.727 & 21.924 & 13.077 & 8.847 & 2.335 & 13,2 \\
III & 9.811 & 13.980 & 6.006 & 7.974 & 1.604 & 16,4 \\
IV & 24.428 & 35.032 & 19.631 & 15.401 & 3.719 & 15,2 \\
V & 25.634 & 34.297 & 18.909 & 15.388 & 4.091 & 16,0 \\
\hline
\end{tabular}

O grupo II apresentou menor variabilidade de precipitação pluvial, tendo a área uma altitude de $350 \mathrm{~m}$. No grupo III a precipitação máxima para o período foi a mais baixa, assim como a média pluviométrica, mas a variabilidade é semelhante ao grupo $\mathrm{V}$ (mais chuvoso que o grupo III).

Oo grupo IV, por sua vez, localizado à montante da bacia em uma altitude de, aproximadamente, $750 \mathrm{~m}$, apresenta uma variabilidade de $15,2 \%$ e conta com a segunda maior precipitação dos grupos. 
Foram gerados também gráficos nos quais são estabelecidos valores de anomalias de precipitações anuais para cada grupo homogêneo em relação à média climatológica.

Quanto aos perídos de ocorrência do El Niño analisados acima, nos anos de 1982 e 1983, no grupo I, a precipitação ultrapassou os 1.000 m em relação à média climatológica; o grupo II não ultrapassou os $400 \mathrm{~mm}$; no grupo III, o ano de 1982 não chegou a $200 \mathrm{~mm}$ e o ano de 1983 não passou dos 500 $\mathrm{mm}$; no grupo IV a precipitação foi de aproximadamente $1.000 \mathrm{~mm}$ como no grupo I, tendo o El Niño marcada influência nessa área, como também no grupo $\mathrm{V}$, chegando a quase $800 \mathrm{~mm}$ de precipitação pluvial.

Nos anos de 1990 a 1993 não houve precipitações tão marcadas nos cinco grupos, havendo pouca variabilidade. Os grupos I, II, IV e V apresentaram escassez de chuvas em alguns dos anos.

Nos anos de 1997 e 1998 os grupos I e V apresentaram as maiores precipitações, chegando a quase $1.000 \mathrm{~mm}$ a mais em relação à média climatológicas. Os demais grupos não ultrapassaram os $300 \mathrm{~mm}$.

Para os períodos de ocorrência do fenômeno La Niña, o ano de 1985 (ano de intenso evento) apresentou déficit de chuvas em todos os grupos. 0 grupo I apresentou maior déficit, chegando a $-1.000 \mathrm{~mm}$ em relação à média climatológica, enquanto as demais áreas não ultrapassaram os $400 \mathrm{~mm}$ negativos.

Os anos de 1988 e 1989 tiveram certa influência, a qual foi diferenciada em cada área. No ano de 1988 a maioria dos grupos obteve valores negativos - apenas o grupo III obteve valor positivo $(100 \mathrm{~mm})$. No ano de 1989 as precipitações foram positivas em todas as áreas.

Para os anos de 2000 e 2001 a influência do evento La Niña foi diferente em cada área. No grupo I obteve-se valor neutro, não havendo variabilidade; no grupo II as precipitações foram negativas, porém não ultrapassaram -200 mm; no grupo III, o ano de 2000 apresentou escassez de chuva, enquanto em 2001 houve superávit; o grupo IV não apresentou muita variabilidade; no grupo $\mathrm{V}$ o ano de 2000 obteve $-400 \mathrm{~mm}$ em relação à média climatológica e em 2001 não houve marcada variabilidade, sendo a precipitação pluvial positiva.

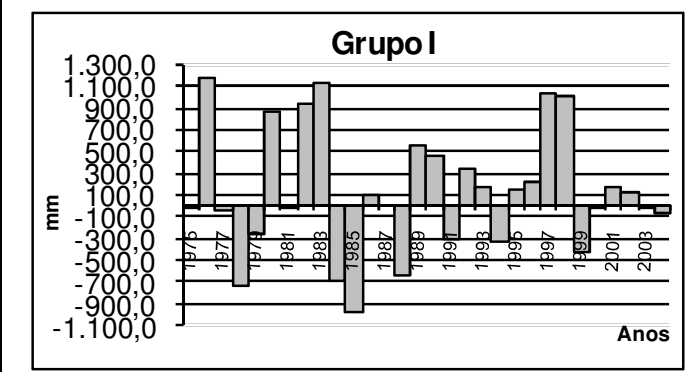

Figura 27: Anomalias de precipitações anuais em relação à média climatológica para o Grupo I.

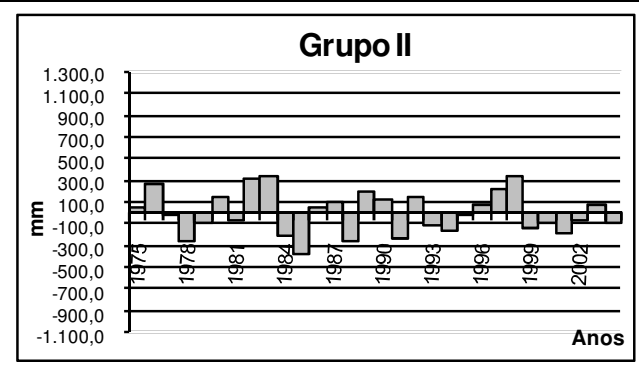

Figura 28: Anomalias de preciptações anuais em relação à média climatológica para o Grupo II. 


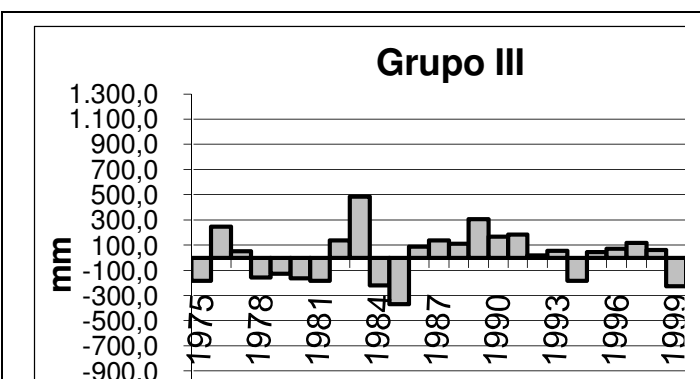

Figura 29: Anomalias de precipitações anuais em relação à média climatológica para o Grupo III.

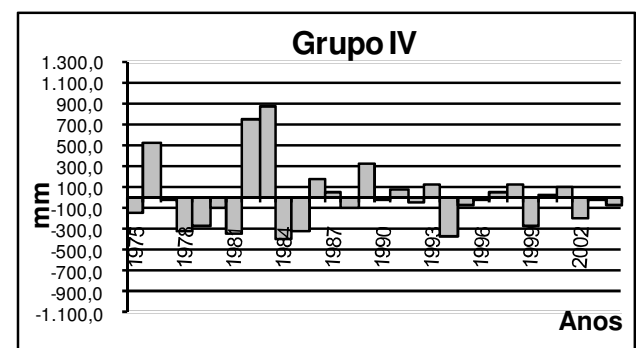

Figura 30: Anomalias de precipitações anuais em relação à média climatológica para o Grupo IV.

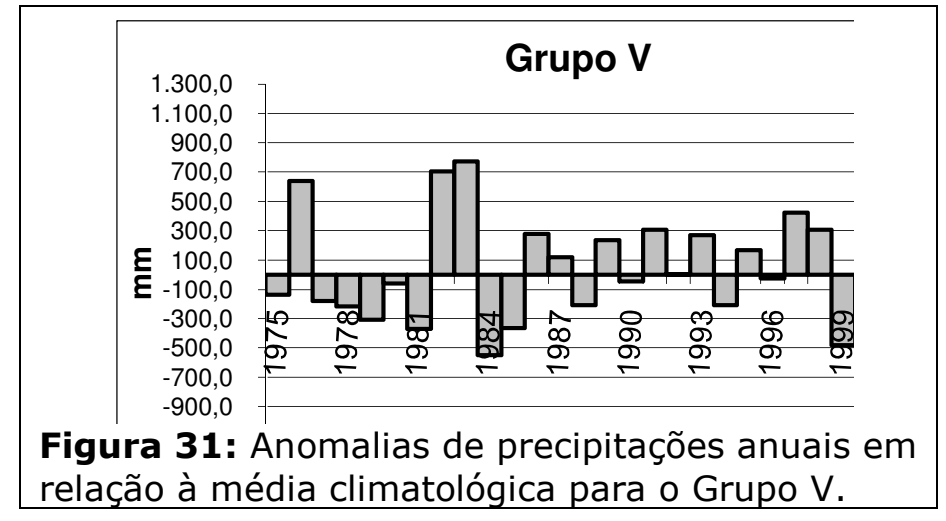

\section{CONCLUSÕES}

Por ser o rio Paranapanema uma fronteira natural entre os Estados de São Paulo e Paraná, ambos apresentando políticas e economias diferenciadas, cada um dês utiliza os recursos hídricos conforme sua necessidade e interesse.

Assim, de acordo com as estatísticas realizadas e com o panorama geográfico da bacia, a precipitação pluvial apresenta significativa variabilidade na área de estudo, com invernos secos e verões chuvosos.

Para o padrão pluviométrico da bacia no período de 1975 a 2004 a média de chuva é maior a Sudoeste da mesma, enquanto no período chuvoso ocorre maior precipitação pluvial a Nordeste da bacia. Já no período seco chove mais ao Sul. Isso, conforme afirmado anteriormente, devido aos sistemas atmosféricos e a orografia.

A variação pluviométrica é muito mais significativa no período seco, chegando a $65 \%$, enquanto no período chuvoso não ultrapassa os $30 \%$, demonstrando uma significativa variabilidade anual e espacial nessa bacia.

A bacia apresenta, em períodos de ocorrência dos fenômenos El Niño e La Niña, variabilidade pluviométrica espacial e temporal, pois os anos de máximos e mínimos, em sua maioria, são considerados anos relacionados a tais fenômenos. Nos anos de 1982, 1983, 1992, 1993, 1997 e 1998 (anos de El Niño), a bacia apresentou anomalias positivas em praticamente todas as áreas analisadas, com valores superiores a $1.300 \mathrm{~mm}$ na região Leste da bacia. Já em 1985, 1988 e 2000 houve déficit de chuvas nessa área, as quais estavam 
associadas a eventos La Niña, com valores negativos chegando a $-300 \mathrm{~mm}$ em algumas áreas, com relação à média climatológica da bacia.

A bacia do Paranapanema, de acordo com a análise multivariada, determinou a existência de cinco grupos homogêneos, constatando que a bacia conta com cinco áreas que apresentaram características diferenciadas entre si.

De acordo com as anomalias de precipitação pluvial em relação à média climatológica, o grupo I se mostrou com maior influência em anos de ocorrência de El Niño e La Niña. Já os outros grupos, apesar de apresentarem influências, não foram tão significativos.

\section{REFERÊNCIAS}

AGÊNCIA NACIONAL DE ÁGUAS - WWW.hidroweb.ana.gov.br. Acessado em dez/2008.

BROWING, K. A. Conceptual model of precipitation system. Meteorological Magazine. 1985; 114(359):293-319.

CPTEC/INPE - http://www.cptec.inpe.br. Acessado em dez/2008.

CUSTÓDIO, M. A. M.; HERDIES, D.L. O jato de baixos níveis a leste da Cordilheira dos Andes - um estudo de caso. In: CONGRESSO BRASILEIRO DE METEOROLOGIA, 8., 1994, Belo Horizonte. Anais. V. 2. Belo Horizonte: FMG, 1994. p. 617-9.

GRIMM A. M.; GUETTER, A. K.; CARAMORI, P. H. EI Niño no Paraná: o que pode esperar em cada região. Uma análise cientifica. SIMEPAR Informativo, 1. 1997

KOUSKY, V. E.; CAVALCANTI, I. F. A. Eventos oscilação sul: El Niño, características, evolução e anomalias de precipitação. Ciência e Cultura. 1984; 36(11): 1888-9.

MENDONÇA, F. Aquecimento global e suas manifestações regionais e locais. Revista

Brasileira de Climatologia, n. 2, p. 71-86, 2007.

MENDONÇA, F.; DANNI-OLIVEIRA, I. M.; Climatologia: noções básicas e climas do Brasil. São Paulo. Oficina de texto. 2007.

NERY, J. T.; MARTINS, M. L. O. F.; VARGAS, M. W. Variabilidade interanual da precipitação do Rio Grande do Sul. Revista Brasileira de Meteorologia, v. 12, n. 1, p. 49-62, 1997.

NIMER, E. Climatologia do Brasil. Rio de Janeiro: IBGE, 1979.

OLIVEIRA, A. S. Interações entre sistemas na América do Sul e convecção na Amazônia. São José dos Campos: INPE, 1986. 
QUADRO, M. F. L.; ABREU, M. L. Estudos de episódios de zonas de convergência do Atlântico Sul sobre a América do Sul. In: Congresso Brasileiro de Meteorologia. Anais. V. 2. Belo Horizonte: FMG, 1994. 620-3.

STUDZINSKI, C. D. Um estudo da precipitação da região sul do Brasil e sua relação com os oceanos Pacífico e Atlântico Tropical Sul. [Tese de mestrado]. São José dos Campos, INPE, 1995. 